\title{
Determinants of Faculty-Student Engagement for Southeast Asian Men in Community College: An Exploratory Analysis
}

\author{
Soua Xiong, $\mathrm{PhD}$ \\ California State University, Fresno, California, United States \\ (iD) https://orcid.org/0000-0002-5582-9022
}

J. Luke Wood, $\mathrm{PhD}$

San Diego State University, San Diego, California, United States

Contact:sxrhs@csufresno.edu

\section{Abstract}

The purpose of this study was to examine determinants of faculty-student engagement for Southeast Asian men in community colleges. Using data derived from the Community College Survey of Men (CCSM), this study investigated faculty-student engagement for 140 Southeast Asian men attending community colleges in the United States. Five groupings of predictor variables were examined: background/defining, campus ethos, environmental, academic, and non-cognitive factors. Backwards multiple linear regression was employed to identify variables with significant contributions to the model. The final model converged on the eighth iteration and significantly predicted the outcome, accounting for $38 \%$ of the variance in faculty-student engagement. Findings indicated that faculty validation, stressful life events, action control, and use of academic advising and career counseling services were significant predictors of faculty-student engagement. Implications for community college practice and research are discussed.

Keywords: Southeast Asian; male of color; community college; faculty-student engagement

Date Submitted: October 19, 2019 | Date Published: July 14, 2020

\section{Recommended Citation}

Xiong, S., \& Wood, J. L. (2020). Determinants of faculty-student engagement for Southeast Asian men in community college: An exploratory analysis. Journal of Educational Research and Practice, 10, 185-198. https://doi.org/10.5590/JERAP.2020.10.1.13.

\section{Introduction}

In recent years, an increasing body of scholarly literature has focused on the experiences, perceptions, and outcomes of men of color in community colleges (e.g., Card \& Wood, 2019; Xiong et al., 2016; Xiong \& Wood, 2018). This scholarship has been motivated by the national discourse on challenges facing boys and men of color in education. Indicative of the intensity of this conversation, the White House launched the My Brother's Keeper Initiative during the Obama Administration to bolster support for programs serving boys and men of color through the support of private donors, foundations, and enhanced partnerships across sectors (The Seven Centers, 2014). Like other sectors of education, community colleges have also struggled to support the 
success of men of color. In fact, Wood et al., (2014) noted that only $17 \%$ of Black and $15 \%$ of Latino men will earn a certificate, degree, or transfer from a community college to a four-year university in three years in comparison to $27 \%$ of White men in that same time frame. While conversations regarding the success of men of color have been advanced among scholars and practitioners, lacking are investigations that focus on nonBlack men of color.

Although limited, a handful of studies have examined the experiences of Latino men (e.g., Falcon et al., 2018; Palacios et. al, 2015; Sáenz et al., 2013; Vasquez Urias, 2012), few studies have specifically addressed the academic realities of Asian American men (e.g., Vang, 2018; Vang \& Wood, 2018; Xiong \& Wood, 2016). Due to the common practice of aggregating Asian ethnic populations, the extent to which postsecondary institutions struggle to facilitate success for Southeast Asian students and specifically for Southeast Asian men is unknown (Maramba, 2011; Museus, 2009; Yeh, 2004-2005). Moreover, the vast majority of scholarship addressing the educational realities of Southeast Asians in higher education has focused on the 4-year college and university context (e.g., Chhuon \& Hudley, 2008; Palmer \& Maramba, 2015; Truong, 2011; Museus, 2013; Vue, 2013; Xiong \& Lee, 2011; Xiong \& Lam, 2013). However, it is critical to examine the experiences and outcomes of Southeast Asians in community colleges because they are more likely to attend community colleges than 4-year colleges and universities (Teranishi, 2010; Xiong, 2019a, 2019b). While Southeast Asians are more likely to attend community college, in comparison to their majority Asian counterparts, they are less likely to earn a degree and "twice as likely to transfer out of school for nonacademic reasons" (Maramba, 2011, p. 129). Based on these findings, extant research on underrepresented men of color would suggest that outcome rates for Southeast Asian men are more alarming (Wood \& Harris, 2014; Wood et al., 2015).

Bearing this in mind, the authors of this study examined determinants of faculty-student engagement for Southeast Asian men in community colleges. In this study, Southeast Asian men refers primarily to men who self-identify as being of Hmong, Cambodian, Laotian, or Vietnamese descent. This study's focus on facultystudent engagement is critical, as prior research on college students, in general, has regularly demonstrated the integral relationship between faculty-student engagement and student success, including enhanced noncognitive outcomes (e.g., motivation, academic-self-conception, satisfaction) (Komarraju et al., 2010; McClenney, 2004), academic performance (e.g., retention, achievement, goal completion) (Bush \& Bush, 2010; Cejda \& Hoover, 2010; Chang, 2005; Cole, 2008, 2010; Pascarella \& Terenzini, 2005; Price \& Tovar, 2014; Thompson, 2001; Wood, 2012a, 2012b) and student learning (Lundberg, 2014; Lundberg \& Shreiner, 2004).

\section{Relevant Literature}

While there has been extensive research on the role of faculty-student engagement on facilitating student success, significantly fewer studies have examined factors that contribute to these interactions. However, these studies do provide a conceptual foundation to this research and inform the conceptual model of facultystudent engagement for Southeast Asian men in the community college (see Figure 1). Using data from immigrant families, Rendón and Valdez (1993) argued that faculty-student engagement was influenced by students' cultural capital. Based on interviews with campus leaders (e.g., college presidents, chief academic officers), participants suggested that students who were less engaged had a more limited understanding of the campus culture and college-level expectations. These leaders situated student engagement as a byproduct of whether students came from families that had prior exposure to college cultures and expectations.

Other scholars have also situated engagement as an outgrowth of students' external pressures. Specifically, Thompson (2001) investigated factors influencing informal interactions with faculty among students attending 56 community colleges. Based on secondary analyses of data from the Community College Student Experiences Questionnaire (CCSEQ), Thompson determined that informal interactions were more likely to 
occur for students who had familial obligations, but that increased time spent working had a negative influence on engagement. It should be noted that the conceptual model tested in this study was primarily limited to external variables (e.g., employment, familial obligations, working), suggesting that the researchers conceptualized engagement as a function of external pressures. Following similar logic, Cotton and Wilson (2006) also examined the role of external pressures on engagement. Based on data derived from focus groups with 49 participants, they found that being enrolled part-time, working while attending college, time spent commuting, and familial obligations had a negative effect on faculty-student engagement.

Other than disparate findings around familial obligations, their research seems to complement findings from Thompson (2001). However, Cotton and Wilson (2006) also found that students were unsure about whether faculty members actually wanted to interact with them. Specifically, students reported that they believe that many faculty members were not receptive to interactions, and as a result, their engagement was limited based upon their perceived receptivity to such interactions. In addition, Cotton and Wilson also extended prior research by addressing the role of structural factors on faculty-student engagement. They noted that institutional characteristics (e.g., built environment, course size) also fostered social dynamics that either facilitated opportunities for enhanced interactions or limited them.

Research from Chang (2005) represents the most comprehensive examination of faculty-student engagement predictors. Using data from the Transfer and Retention of Urban Community College Students (TRUCCS) survey of 2,500 respondents, Chang identified numerous determinants of engagement. Although being older, having parents who have completed higher levels of education, and spending more time on campus were predictors of faculty-student engagement for all other racial student groups, they were not predictors of faculty-student engagement for Asian American and Pacific Islander students. Chang concluded that Asian American and Pacific Islander students who engaged with faculty were more likely to be determined and confident, to study with others, speak with an academic counselor, study alone, and to report that teachers encouraged them in their academic studies. However, they were less likely to attend orientation, spend time on campus, and to perceive hardships due to their race/ethnicity. While insightful, Chang's study encompassed a wide array of Asian American and Pacific Islander student ethnic groups.

Unfortunately, it is unclear how Chang's (2005) findings may have differed across ethnic groups. For example, Chang found that students who met with academic counselors were more likely to engage with faculty. However, research from Xiong and Lam (2013) on Hmong college students has shown that they do not perceive academic counselors as being part of their support system. Other research on Hmong undergraduate students has shown that they often have negative experiences with academic counselors (Xiong \& Lee, 2011). Given this, it is plausible that disaggregation of findings across Asian groups may produce more nuanced understandings of factors that influence faculty-student engagement. This represents one important contribution of this study to prior literature.

The aforementioned literature served as a conceptual lens for this current investigation, particularly the works of Chang (2005) and Cotton and Wilson (2006). Based on prior research, a conceptual model of facultystudent engagement for Southeast Asian men in the community college was developed. This model suggests that faculty-student engagement for Southeast Asian men is influenced by campus ethos factors (representing the campus climate and culture) and background/defining factors (accounting for students' demographic characteristics and goal expectations). These factors are hypothesized to directly influence faculty-student engagement, but also filter through the remaining factors in the model, as indirect effects. The model depicts a multi-directional effect of environmental factors (pressures that occur outside of college), academic factors (endemic of students use of services), and psychosocial factors (accounting for non-cognitive outcomes). These factors are perceived to influence one another and faculty-student engagement. Though the model depicts specific linkages between each factor, the focus of this research is on the predictive utility of the variables within the model. The analytic procedures used to test this model are described in the next section. 


\section{Methods}

Data from this study were derived from the Community College Survey of Men (CCSM). The CCSM is an institutional-level needs assessment instrument that has been employed at more than 50 colleges in eight states to better understand factors influencing student success outcomes for men of color. The instrument was designed based on an extensive review of research on college men and masculinities, men of color in community colleges, and identity development. The instrument was subjected to a three-phase, two-year long pilot process to evaluate and refine the validity and reliability of the instrument. The results from this pilot phase indicated that the instrument has strong psychometric properties, based upon content, construct, and confirmatory validity (De la Garza et al., 2015; Harris et al., 2015; Wood \& Harris, 2013; Wood et al., 2017). While approximately 7,000 men have participated in the CCSM, a smaller portion ( $n=551)$ of men of Asian descent have done so. Of these men, 140 men of Southeast Asian descent have completed the instrument. This study employs responses from these men.

The outcome variable employed in this study was faculty-student engagement. This composite variable was derived from students' responses to four questions regarding the frequency of their interactions with faculty regarding in- and out-of-class academic and non-academic matters $(\alpha=.89)$. Five groupings of predictor variables (based on the conceptual model employed in this study) were examined in this study, addressing background/defining, campus ethos, environmental, academic, and non-cognitive factors (see Figure 1 for coding schema). Background/defining variables included students' age, annual income, and highest degree goal. Campus ethos variables assessed student's perceptions of the campus climate and culture. This domain included composite variables for students' perceptions of sense of belonging with faculty $(\alpha=.94)$, validation from faculty $(\alpha=.92)$, validation from staff $(\alpha=.96)$, perceptions of access to campus services $(\alpha=.90)$, and

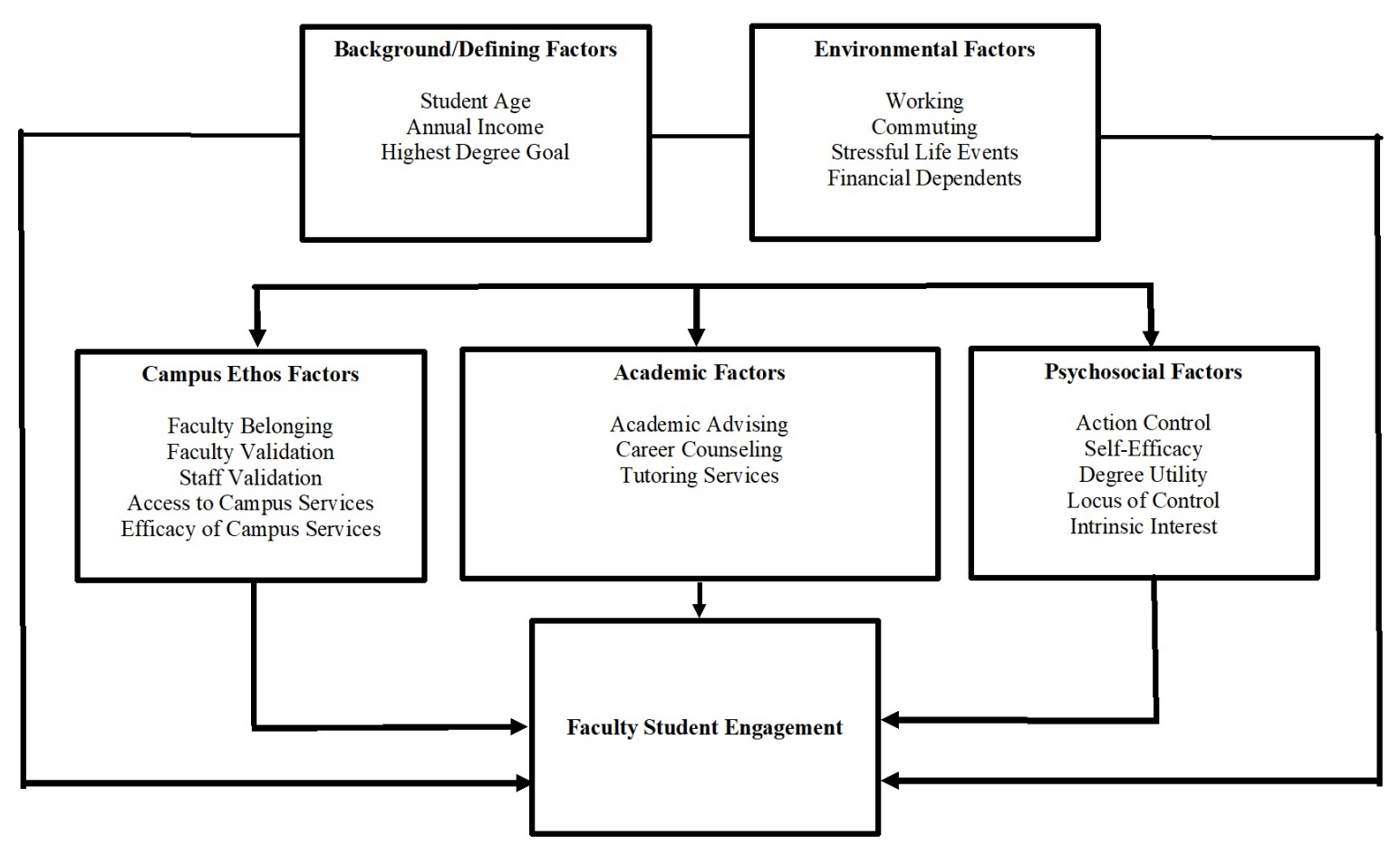

Figure 1: Conceptual Model of Faculty-Student Engagement for Southeast Asian Men in the Community College 
perceptions of the efficacy of campus services $(\alpha=.88)$. The composites and items for these campus ethos variables are presented in Table 1.

Table 1: Composites and Items of Campus Ethos Variables

\begin{tabular}{|c|c|c|}
\hline Composite Variables & Individual Items & $\begin{array}{c}\text { Cronbach's } \\
\text { Alpha }\end{array}$ \\
\hline Faculty Belonging & $\begin{array}{l}\text { Faculty care about my perspective in class. } \\
\text { Faculty value interacting with me during class. } \\
\text { Faculty value my presence in class. } \\
\text { Faculty care about my success in class. } \\
\text { Faculty believe I belong here. }\end{array}$ & .94 \\
\hline Faculty Validation & $\begin{array}{l}\text { Professor who regularly tells me that I have the ability to do } \\
\text { the work. } \\
\text { Professor who regularly tells me that I can succeed in } \\
\text { college. } \\
\text { Professor who regularly tells me that I belong at this } \\
\text { institution. }\end{array}$ & .92 \\
\hline Staff Validation & $\begin{array}{l}\text { Staff member who regularly tells me that I have the ability } \\
\text { to do the work. } \\
\text { Staff member who regularly tells me that I can succeed in } \\
\text { college. } \\
\text { Staff member who regularly tells me that I belong at this } \\
\text { institution. }\end{array}$ & .96 \\
\hline $\begin{array}{l}\text { Access to Campus } \\
\text { Resources }\end{array}$ & $\begin{array}{l}\text { The campus services I need for success are easy to access. } \\
\text { I know which campus services to go to for help. } \\
\text { The campus services I need for success are available when I } \\
\text { need them. }\end{array}$ & .90 \\
\hline $\begin{array}{l}\text { Efficacy of Campus } \\
\text { Resources }\end{array}$ & $\begin{array}{l}\text { Campus services provide me with the help I need. } \\
\text { Campus services provide me with accurate information. } \\
\text { Campus services are critical to my success. }\end{array}$ & .88 \\
\hline
\end{tabular}

The environmental domain was comprised of factors that occurred outside of college that influenced student success inside of college. The variables in this domain included total stressful life events in the past two years (e.g., divorce, relationship breakup, incarceration, eviction, loss of a job), total number of financial dependents, hours per week spent working and hours per week spent commuting to and from campus. The academic domain included three measures of student's use of campus services. The frequency of service use was assessed for academic advising, career counseling, and tutoring services. The final domain assessed a range of psychosocial/non-cognitive outcomes. The non-cognitive factors included the following composite variables: action control (students directed attention/focus on academic matters) ( $\alpha=.93$ ), self-efficacy (students' confidence in their academic abilities) ( $\alpha=.93$ ), locus of control (students' perceptions of control over their academic futures) $(\alpha=.94)$, intrinsic interest (students' authentic interest in academic content and learning) ( $\alpha=.92$ ), and degree utility (students' perceptions of the worthwhileness of their collegiate 
endeavors) ( $\alpha=.88$ ) (see De la Garza at al. (2015) for definitions). The composites and items for these psychosocial variables are presented in Table 2.

Table 2: Composites and Items of Psychosocial Variables

\begin{tabular}{|c|c|c|}
\hline $\begin{array}{l}\text { Composite } \\
\text { Variables }\end{array}$ & Individual Items & $\begin{array}{l}\text { Cronbach's } \\
\text { Alpha }\end{array}$ \\
\hline \multirow[t]{4}{*}{ Action Control } & I am completely focused on school. & .93 \\
\hline & I work as hard as I can to earn good grades in all my classes. & \\
\hline & I put forth my best effort in school. & \\
\hline & I am driven to be successful in school. & \\
\hline \multirow[t]{4}{*}{ Degree Utility } & $\begin{array}{l}\text { The time I spend in school will help me achieve my personal } \\
\text { goals. }\end{array}$ & .88 \\
\hline & Attending college will provide me with financial security. & \\
\hline & Attending college will increase my job opportunities. & \\
\hline & Attending college will create a better life for me and my family. & \\
\hline \multirow[t]{4}{*}{ Self-Efficacy } & I have the ability to excel in my coursework. & .93 \\
\hline & I can understand difficult concepts. & \\
\hline & I can master the material in my courses. & \\
\hline & I am confident in my academic abilities. & \\
\hline \multirow[t]{4}{*}{ Locus of Control } & If I study hard enough, I’ll get good grades. & .94 \\
\hline & I have full control over my own academic success. & \\
\hline & I have power to get good grades when I want to. & \\
\hline & My academic success is in my own hands. & \\
\hline \multirow[t]{3}{*}{ Intrinsic Interest } & I enjoy learning from my classes. & .92 \\
\hline & What I learn in class is interesting. & \\
\hline & $\begin{array}{l}\text { I want to learn as much as I can in school. } \\
\text { I get totally absorbed in my coursework. }\end{array}$ & \\
\hline
\end{tabular}

Data employed in this study were analyzed in three stages. In the first stage, exploratory data analysis was conducted to evaluate the characteristics of the data. Primarily, this included an analysis of descriptive statistics (e.g., means, standard deviations, frequencies). In the second analytic stage, correlations among study variables with a focus on correlates of faculty-student engagement were examined. This information was used to delimit the variables examined in subsequent stages to include only those variables that had a significant association with the outcome. Correlates of engagement are identified in the model with the symbol $(*)$. In the final analytic stage, backwards multiple linear regression was employed to examine determinants of faculty-student engagement among the study variables. Variables identified as being significantly predictive of the outcome are denoted in Figure 2 with the symbol $(\dagger)$. Tolerance and variation inflation factors (VIFs) were within stable regions. The degree of missingness was less than $5.0 \%$. This percentage of missingness was negligible. Given this, missing values were replaced using the expectationmaximization procedure. 


\section{Results}

During exploratory data analysis, general characteristics of the data were examined. For example, the majority of the sample (59.2\%) was between 18 and 24 years of age followed by 25 to 31 years old (18.6\%). The remainder of the sample was above this age range. In terms of income, slightly more than half of the sample (51.4\%) had annual household incomes of $\$ 10$,ooo per year or less, with another $19.3 \%$ with incomes ranging between $\$ 10,001$ to $\$ 20,000$ per year. As such, half of the sample would be characterized as low-income. In addition, $27.1 \%$ of the sample support financial dependents (e.g., children, siblings, parents, grandparents) with the majority of these having 2 or more financial dependents. Moreover, many of the participants in the sample were first-generation college students, with only $25.7 \%$ of fathers and $16.4 \%$ of mothers possessing college degrees.

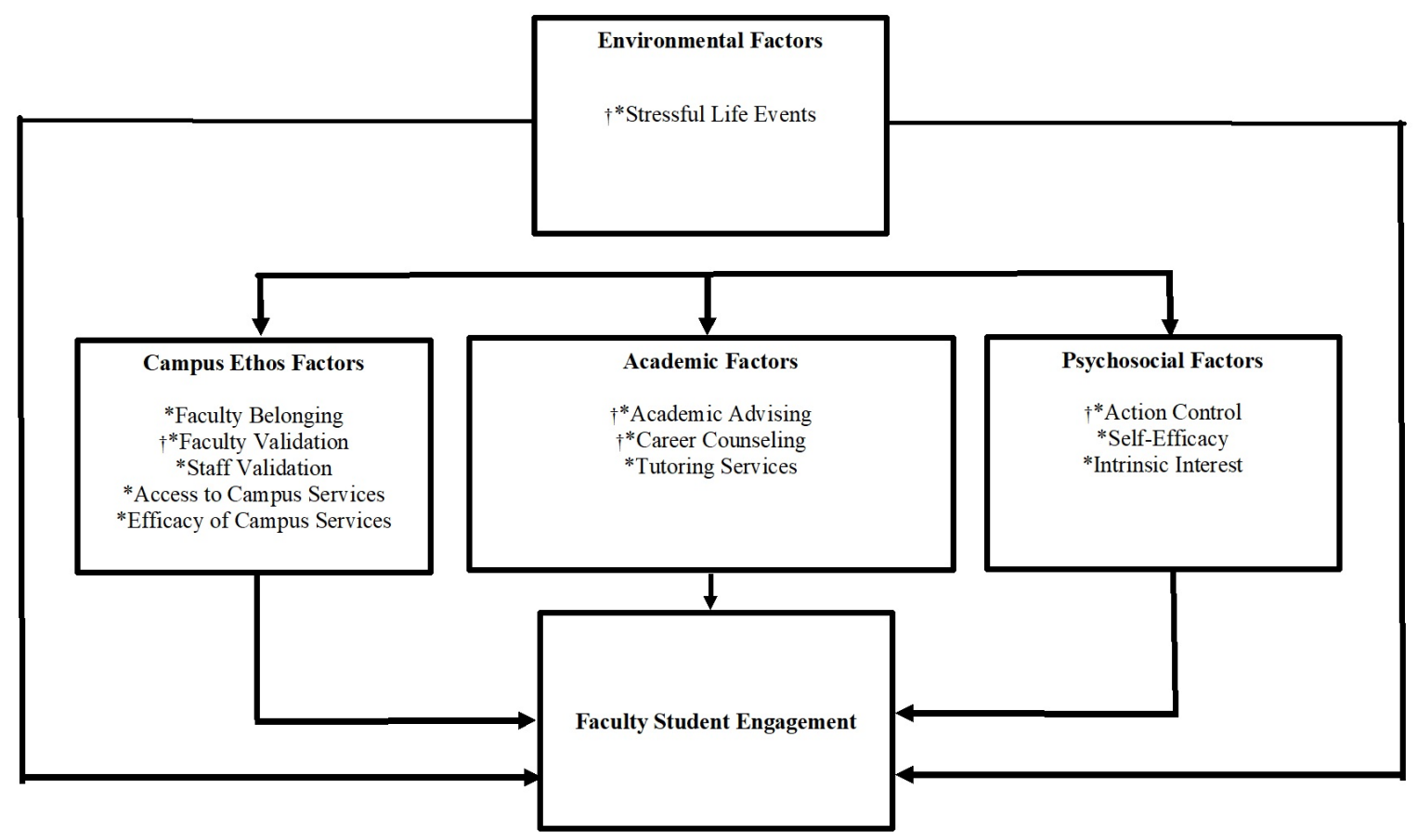

Note: ${ }^{*}=$ correlate of faculty-student engagement; $\dagger=$ predictor of faculty-student engagement

Figure 2. Determinants of Faculty-Student Engagement for Southeast Asian Men in the Community College

Of the 20 total variables examined, 12 had a significant association with faculty-student engagement. None of the background/defining variables had a statistically significant relationship with the outcome variable. Students' perceptions of belonging with faculty $(\mathrm{r}=.32, \mathrm{p}<.001)$ were positively correlated with facultystudent engagement, as were their experiences in being validated by faculty members $(\mathrm{r}=.40, \mathrm{p}<.001)$. As with faculty validation, greater levels of staff validation were also correlated with the outcome $(\mathrm{r}=.43, \mathrm{p}<$ .001). In addition, having a greater perception of access to campus services $(r=.28, p<.001)$ and the efficacy of those services $(\mathrm{r}=.31, \mathrm{p}<$.001) in addressing student needs were positively correlated with engagement. In terms of the environmental variables, only one was a significant correlate of faculty-student engagement. Students with greater levels of stressful life events had more frequent engagement with their faculty $(r=.27$, 
$\mathrm{p}=.002)$. With respect to the academic domain, all three measures of service use were correlates of the outcome. Students who used academic advising $(\mathrm{r}=.43, \mathrm{p}<.001)$, career counseling $(\mathrm{r}=.34, \mathrm{p}<.001)$, and tutoring services $(\mathrm{r}=.36, \mathrm{p}<.001)$ were also often more likely to engage with faculty. Finally, three of the non-cognitive variables were significantly correlated with engagement. Specifically, students who placed greater attention/focus on academic matters (referred to as action control) $(\mathrm{r}=.25, \mathrm{p}=.003$ ), had higher levels of self-efficacy $(\mathrm{r}=.18, \mathrm{p}=.036)$, higher levels of intrinsic interest $(\mathrm{r}=.17, \mathrm{p}=.037)$, and were also more likely to engage with their faculty.

Variables identified as having a significant association with faculty-student engagement were retained for inclusion in the subsequent analysis. Backwards multiple linear regression was employed to enable the researchers to identify variables with significant contributions to the model. The initial model significantly predicted the outcome $(\mathrm{F}(12,127)=7.86, \mathrm{p}<.001)$ and accounted for $37 \%$ of the variance in faculty-student engagement. While all subsequent models did not significantly improve the predictability of the initial model, they produced more parsimonious models. The final model converged on the eighth iteration and significantly predicted the outcome $(\mathrm{F}(5,134)=18.35, \mathrm{p}<.001)$, accounting for $38 \%$ of the variance in the outcome.

Of the 13 variables employed, five were retained as significant determinants of faculty-student engagement. Faculty validation was found to be a significant determinant of faculty-student engagement $(\mathrm{t}=4.47, \mathrm{p}<$ .001). As such, greater levels of validating messages from faculty were predictive of greater faculty-student engagement. Stressful life events were also identified as being predictive of the outcome $(t=3.97, p<.001)$. More frequent stressful life events predicted higher scores for faculty-student engagement. Action control also emerged as a significant determinant of the outcome $(t=3.61, \mathrm{p}<.001)$. Thus, when students placed greater levels of focus/effort on academic matters, they were more likely to be engaged with faculty. Finally, use of academic advising $(t=2.18, \mathrm{p}=.031)$ and career counseling $(\mathrm{t}=2.57, \mathrm{p}=.011)$ services were also significant predictors of engagement with faculty members. The next section contextualizes these findings with the extant literature on faculty-student engagement.

\section{Discussion}

This study set out to identify determinants of faculty-student engagement for Southeast Asian men in the community college. Correlation analyses indicated that there were twelve variables that had an association with the outcome. These variables included: sense of belonging with faculty, faculty validation, staff validation, access to campus services, efficacy of campus services, stressful life events, action control, selfefficacy, intrinsic interest, as well as use of academic advising, career counseling, and tutoring services. These variables were identified as having a positive association with faculty-student engagement. As demonstrated in Figure 2, most variables that had a relationship with the outcome were campus ethos factors. In general, these associations demonstrated that there is a relationship between positive campus climates and cultures on faculty-student engagement.

Subsequent regression analyses indicated that, of the variables retained for the regression models, faculty validation, stressful life events, action control, and use of academic advising and career counseling services significantly predicted the outcome. As such, when faculty members communicated messages to students that they have the ability to perform and succeed in college, Southeast Asian male students in this study were significantly more likely to engage with faculty. This finding aligns with prior research from Bauer (2014) who examined differential levels of faculty-student engagement for Black men in community colleges. As noted earlier, her research found that Black men experienced greater levels of engagement with faculty as their levels of validation from faculty increased. Collectively, findings from Bauer (2014) and this study extend scholars' understanding of the multiplicative benefits of validation. The researchers suggest that validation creates positive conditions that allow, enable, and encourage students to engage with faculty members. While 
Rendón (1994) noted that validation fosters positive student attitudes and academic development, findings from this study suggest that engagement with faculty is also an outgrowth of validating messages from faculty.

In addition, action control was also a determinant of faculty-student engagement. This suggests that Southeast Asian men in this sample who are more focused on academic matters and place greater effort into their studies are significantly more likely to be engaged with faculty members. This is in line with prior research that establishes a relationship between faculty-student engagement and student effort (e.g., Lundberg \& Schreiner, 2004; Wood \& Palmer, 2014). As noted earlier, Wood and Palmer found that Black men who described themselves as being more focused in the community college noted that "establishing bonds with faculty members" was precipitated by their focus in school (p. 148). The researchers suggest that students who exhibit high action control may feel more in control of their academic performance through selfmonitoring strategies and exert more effort to actively engage with faculty for assistance as needed.

Furthermore, use of campus services was a significant predictor of faculty-student engagement, particularly use of academic advising and career counseling services. This result suggests that when students use academic and career-related services more frequently, they also engaged with faculty members more often. Possibly, students who use these services are more likely to be engaged with faculty, as they have generally higher levels of engagement. It is also possible that staff in these services are in positions that allow them to guide students on how to approach engaging interactions with faculty. This provides support for previous research from Chang (2005) that Asian American and Pacific Islander community college students who engage with faculty were also more likely to engage with counselors. Moreover, this result advances our understanding of the relationship between campus service use and faculty-student engagement.

Finally, this research has also indicated that stressful life events were a significant predictor of the outcome. Interestingly, this suggests that as students are exposed to greater major stressful life events (e.g., divorce, relationship breakup, incarceration, eviction, death in the family), they have greater levels of engagement with faculty members. Few prior studies have examined the effect of stressful life events on faculty-student engagement. However, research from Cotton and Wilson (2006) found that increased external pressures (e.g., familial obligations, financial pressures, working, commuting) was attributed by students as having an adverse relationship on their engagement with faculty. Following this logic, the authors assumed that stressful life events (which seemingly represent intensified external pressures) would have been a negative determinant of engagement. However, for the Southeast Asian male students in this study, the opposite relationship was identified. There are numerous and competing rationales that could explain this finding. Possibly, students who experience more stressful life events are more proactive in seeking out support from faculty members. Therefore, the stress serves as an impetus for student-initiated contact. Juxtaposed to this possibility, is that when students encounter greater levels of stressful life events, faculty members become attuned to the challenges that they are facing and are interceding to provide a reasonable level of support. Clearly, further inquiry is necessary to better understand this relationship.

\section{Implications for Practice}

Findings from this study indicate that faculty validation, stressful life events, action control, and use of academic advising and career counseling services were significant predictors of faculty-student engagement for Southeast Asian men in community colleges. Therefore, community colleges should provide opportunities for engagement and access to faculty members who can help these men address these five areas. Prior research on men of color in the community college has shown that due to cultural and masculine norms, they may be apprehensive about sharing personal information with campus professionals, particularly if these professionals do not have a relationship with them (Wood et al., 2015). It is incumbent upon faculty members to develop personal relationships with these men that would enable them to proactively address potential life 
stressors facing students and refer them to appropriate personal counseling support. In developing personal relationships, Wood et al. (2015) underscored the importance for faculty members to understand cultural considerations and their own biases when engaging with this student population.

Second, Southeast Asian men who place greater attention and focus on academic matters were more likely to engage with their faculty. Given this, community colleges should provide opportunities for these men to develop high action control in their academics. Research from Wood and Palmer (2014) demonstrates that involvement in campus clubs and organizations and full-time enrollment were factors that community college men of color described as leading to enhanced action control. Thus, the researchers recommend that academic advisors and counselors encourage students to be involved in campus clubs and organizations. However, given that social involvement can serve as a negative determinant of student success for men of color in community colleges (Bush \& Bush, 2010; Wood, 2012b), it is recommended that those advising students on becoming involved be judicious in restricting their referrals to only include student organizations that are closely aligned with students' academic goals. Otherwise, increased involvement may detract from the time students have to place on academic matters, particularly for those who are part-time, commuting, or have dependents.

Moreover, Southeast Asian men who receive validation from faculty were also more likely to engage with their faculty. Therefore, community colleges should provide opportunities for faculty members to engage in professional development on how to authentically validate historically underrepresented and underserved students, particularly Southeast Asian men. Comprehensively, this should include validation around students' presence in college, cultural knowledge(s), learning abilities, experiences, and future goals (Rendón, 1994).

Lastly, Southeast Asian men who use academic advising and career counseling services more often were also more likely to engage with faculty members. Thus, the researchers recommend the use of intrusive advising and support models that require students to use campus services. Intrusive models can be supported by institutional policies (e.g., early alert, probation/retention agreements) and programming (e.g., learning communities, retention programs) that foster use of these services in a manner which reconnects to students' engagement in and out of the classroom with faculty.

\section{Limitations and Implications for Future Research}

As with other studies, this study had limitations. The CCSM instrument was designed to examine factors affecting the success of men of color in the community college. However, as previously noted, the majority of this research was on Black men. Thus, the utility of this instrument in addressing the cultural and ethnic factors specific for men of Southeast Asian descent is unclear. As such, future qualitative research is needed to explore these factors. In particular, grounded theory qualitative studies are needed to better theorize the factors influencing engagement for Southeast Asian students. Moreover, these studies should be attentive to cultural, masculine, and ethnic nuances that may not be readily examined through analysis of secondary data. Finally, this study was also limited in that men of Southeast Asian descent were collapsed into one group for analysis. This was done due to sample size limitations; however, this approach may mask factors that are unique to the various ethnic groups (e.g., Hmong, Cambodian, Laotian, Vietnamese) included in the sample. As such, additional data should be collected via the CCSM and other instruments that will eventually allow for sample disaggregation by Southeast Asian ethnic backgrounds.

Despite these limitations, this research has extended the current trajectory of research on men of color in the community college to examine the engagement of Southeast Asian men. Given that Southeast Asian students are more likely to attend community colleges than 4-year institutions (Teranishi, 2010); this study provides necessary insight for further research in this area. Considering the critical influence of engagement with 
faculty on student success, this study has provided integral insight on one critical element of student success for these men.

\section{References}

Bauer, K. (2014). Black male community college students and faculty-student engagement: Differences in faculty validation and time status. Journal of Progressive Policy and Practice, 2(2), 157-164.

Bush, E. C. \& Bush, L. (2010). Calling out the elephant: An examination of African American male achievement in community colleges. Journal of African American Males in Education 1(1), 40-62.

Card, P., \& Wood, J. L. (2019). The impact of faculty validation on male students of color at community college. Community College Journal of Research and Practice, 43(5), 386-389.

Cejda, B. D. \& Hoover, R. E. (2010). Strategies for faculty-student engagement: How community college faculty engage Latino students. Journal of College Student Retention, 12(2), 135-153.

Chang, J. C. (2005). Faculty-student interaction at the community college: A focus on students of color. Research in Higher Education, 46(7), 769-802.

Chhuon, V. \& Hudley, C. (2008). Factors supporting Cambodian American students' successful adjustment to the university. Journal of College Student Development, 49(1), 15-30.

Cole, D. (2008). Constructive criticism: The role of student-faculty interactions on African American and Hispanic students' educational gains. Journal of College Student Development, 49(6), 587-605.

Cole, D. (2010). The effects of student-faculty interactions on minority students' college grades: Differences between aggregated and disaggregated data. The Journal of the Professoriate, 3(2), 137-160

Cotton, S. R., \& Wilson, B. (2006). Student-faculty interactions: Dynamics and determinants. Higher Education, 51(4), 487-519.

De la Garza, T., Wood, J. L., \& Harris F., III. (2015): An exploratory assessment of the validity of the Community College Survey of Men (CCSM): Implications for serving veteran men, Community College Journal of Research and Practice, 39(3), 293-298.

Falcon, V., Harris, F., Leal, U., \& Vasquez, M. (2018). An intersectional multicultural approach to advising and counseling transborder Mexican-American men in the community college. New Directions for Student Services, 164, 73-83.

Harris, F., Wood, J. L., \& Newman, C. (2015). An exploratory investigation of the effect of racial and masculine identity on focus: An examination of White, Black, Mexicano, Latino, and Asian men in community colleges. Culture, Society, \& Masculinities, 7(1), 61-72.

Komarraju, M., Musulkin, S., \& Bhattacharya, G. (2010). Role of student-faculty interactions in developing college students' academic self-concept, motivation, and achievement. Journal of College Student Development, 51(3), 332-342.

Lundberg, C. A. (2014). Peers and faculty as predictors of learning for community college students. Community College Review, 42(2), 79-98.

Lundberg, C. A., \& Schreiner, L. A. (2004). Quality and frequency of faculty-student interaction as predictors of learning: An analysis by student race/ethnicity. Journal of College Student Development, 45(5), $549-565$.

Maramba, D. C. (2011). The importance of critically disaggregating data: The case of Southeast Asian American students. AAPI Nexus, 9, 127-133. 
McClenney, K. M. (2004, November/December). Redefining quality in community colleges: Focusing on good educational practice. Change, 16-21.

Museus, S. D. (2009). A critical analysis of the invisibility of Southeast Asian American students in higher education research and discourse. In L. Zhan (Ed.), Asian voices: Engaging, empowering, and enabling (59-76). NLN Press.

Museus, S. D. (2013). Unpacking the complex and multifaceted nature of parental influences on Southeast Asian American college students' educational trajectories. Journal of Higher Education, 84(5), 708738.

Palacios, A. M. G., Wood, J. L., \& Harris F., III (2015). Mexicano male students' engagement with faculty in the community college. In D. Mitchell, Jr., K. M. Soria, E. A. Daniele, \& J. A. Gipson (Eds.), Student involvement and academic outcomes (pp. 185-200). Peter Lang.

Palmer, R. T., \& Maramba, D. C. (2015). The impact of social capital on the access, adjustment, and success of Southeast Asian American college students. Journal of College Student Development, 56(1), 45-60.

Pascarella, E. T., \& Terenzini, P. T. (2005). How college affects students. Jossey-Bass.

Price, D. V. \& Tovar, E. (2014). Student engagement and institutional graduation rates: Identifying highimpact educational practices for community colleges. Community College Journal of Research and Practice, 38(9), 766-782.

Rendón, L. I. (1994). Validating culturally diverse students: Toward a new model of learning and student development. Innovative Higher Education, 19(1), 33-51.

Rendón, L. I., \& Valdez, J. R. (1993). Qualitative indicators of Hispanic student transfer. Community College Review, 2O(4), 27-37.

Saenz, V. B., Bukoski, B. E., Lu, C., \& Rodriguez, S. (2013). Latino males in Texas community colleges: A phenomenological study of masculinity constructs and their effect on college experiences. Journal of African American Males in Education, 4(2), 82-102.

Teranishi, R. T. (2010). Asians in the ivory tower: Dilemmas of racial inequality in American higher education. Teachers College Press.

The Seven Centers Report (2014). Advancing the success of boys and men of color: Recommendations for policy makers. Contributions from the Center for the Study of Race and Equity in Education, Minority Male Community College Collaborative, Morehouse Research Institute, Project MALES and the Texas Education Consortium for Male Students of Color, Todd Anthony Bell National Resource Center on the African American Male, Black Male Institute, Wisconsin's Equity and Inclusion Laboratory. https://diversity.utexas.edu/projectmales/wp-content/uploads/2014/o8/POLICYREPORT-8-29-141-copy.pdf

Thompson, M. D. (2001). Informal student-faculty interaction: Its relationship to educational gains in science and mathematics among community college students. Community College Review, 29(1), 35-57.

Truong, K. K. (2011). Acculturation, cultural capital, and social capital: Understanding 1.5 and 2nd generation Laotian-American female college achievement. Voices of Claremont Graduate University Student Research Journal, 1, 196-229.

Vang, M. (2018). Examining predictors of faculty-student engagement inside and outside the classroom for Southeast Asian American men in community college. Journal of Applied Research in the Community College, 25(1), 17-26.

Vang, M., \& Wood, J. L. (2018). Exploring racial/ethnic identity and enrollment status on noncognitive outcomes among Asian American and Pacific Islander men in community college. The Community College Enterprise, 24(1), 20-33. 
Vasquez Urias, M. (2012). The impact of institutional characteristics on Latino male graduation rates in community colleges. Annuals of the Next Generations, 3(1), 1-12.

Vue, R. (2013). Understanding Hmong American students' experiences negotiating identity and higher education. In S. D. Museus, D. C. Maramba, \& R. T. Teranishi (Eds.), The minority within the minority: Asian Americans in higher education. Stylus Publishing.

Wood, J. L. (2012a). Black males in the community college: Using two national datasets to examine academic and social integration. Journal of Black Masculinity, 2(2), 56-88.

Wood, J. L. (2012b). Examining academic variables affecting the persistence and attainment of Black male collegians: A focus on performance and integration in the community college. Race Ethnicity and Education, 17(5), 601-622.

Wood, J. L. \& Harris F., III (2013). The community college survey of men: An initial validation of the instrument's non-cognitive outcomes construct. Community College Journal of Research and Practice, 37, 333-338.

Wood, J. L., \& Harris F., III (2014). Picturing inequity: An infographic report on persistence and completion for men in the California community college. San Diego, CA: Minority Male Community College Collaborative (M2C3).

Wood, J. L., Harris F., III, \& Mazyck, J. (2015). Picturing inequity: An infographic report on remediation for men in the California community college. San Diego, CA: Minority Male Community College Collaborative $\left(\mathrm{M}_{2} \mathrm{C}_{3}\right)$.

Wood, J. L., Harris, F., \& Roesch, S. C. (2017). Validation of the Community College Survey of Men: An overview of the intrapersonal factors in the noncognitive domain. Journal of College Student Development, 58(8), 1267-1274.

Wood, J. L., Harris, F., \& White, K. (2015). Teaching men of color in the community college: A guidebook. Montezuma.

Wood, J. L., Harris F., III, \& Xiong, S. (2014). Advancing the success of men of color in the community college: Special issue on the Community College Survey of Men (CCSM). Journal of Progressive Policy and Practice, 2(2), 129-133.

Wood, J. L., \& Palmer, R. T. (2014). Academic achievement and the community college: Perspectives of Black male students on the importance of "focus." College Student Affairs Journal, 32(1), 141-154.

Xiong, S. (2019a). Use of campus services among Southeast Asian American community college students: A structural equation modeling analysis (Unpublished doctoral dissertation). Claremont Graduate University.

Xiong, S. (2019b). Access, use, and efficacy of campus services among Hmong American community college students. Journal of Applied Research in the Community College, 26(1), 73-88.

Xiong, S., Allen, C., Wood, J. L. (2016). The role of community college counselors as validating agents on men of color student success. Community College Journal of Research and Practice, 4O(6), 558-561.

Xiong, S. \& Lam, S. K. Y. (2013). Factors impacting the success of Hmong college students in America. British Journal of Guidance and Counselling, 41(2), 132-144.

Xiong, S., \& Lee, S. E. (2011). Hmong students in higher education and academic support programs. Hmong Studies Journal, 12, 1-20.

Xiong, S., \& Wood, J. L. (2016). Non-cognitive predictors of help-seeking among Southeast Asian men in community colleges. Community College Journal of Research and Practice, 4O(5), 452-455. 
Xiong, S., \& Wood, J. L. (2018). Perceptions of faculty welcoming engagement among African-American male students in the community college. In T. N. Ingram \& J. Coaxum (Eds.), Engaging African American males in community college (pp. 3-20). Information Age.

Yeh, T. L. (2004-2005). Issues of college persistence between Asian and Asian Pacific American students. Journal of College Student Retention, 6(1), 81-96. about developments and change in the field of education and learning. The journal includes research and related content that examine current relevant educational issues and processes. The aim is to provide readers with knowledge and with strategies to use that knowledge in educational or learning environments. JERAP focuses on education at all levels and in any setting, and includes peer-reviewed research reports, commentaries, book reviews, interviews of prominent individuals, and reports about educational practice. The journal is sponsored by the Richard W. Riley College of Education and Leadership at Walden University, and publication in JERAP is always free to authors and readers. 